\title{
Identidad religiosa y autoridad política en el Martirio de Zebinas (BHO 531, BHG 942) Circulación y adaptación de motivos polémicos entre Bizancio y la Persia sasánida
}

\section{Religious Identity and Political Authority in the Martyrdom of Zebina (BHO 531, BHG 942): Circulation and Adaptation of Polemical Motives between Byzantium and Sasanian Persia}

\author{
(4) Héctor R. Francisco \\ IMHICIHU, CONICET / Universidad de Buenos Aires, Argentina \\ hectorfrancisco@conicet.gov.ar
}

Recibido: 10-12-2019. Aceptado: 04-02-2020.

\begin{abstract}
Resumen
El objetivo de este trabajo es analizar el proceso de traducción/adaptación y circulación de la literatura martirial sirio-oriental en el Imperio romano oriental entre los siglos V y VII. En particular, haremos algunas observaciones en torno a las circunstancias de traducción y difusión de dicha literatura y las condiciones que determinaron su recepción. Como hipótesis de trabajo, sostendremos que dicha circulación involucró un proceso complejo de adaptación que comprendía diversas estrategias. En segundo lugar, nos proponemos explorar un aspecto concreto de este proceso: la transmisión de los motivos hagiográficos relacionados con el origen de la autoridad monárquica y los límites de la obediencia debida por los súbditos cristianos a un monarca pagano.
\end{abstract}

Palabras clave

martirio

cristianismo

antigüedad tardía Imperio sasánida Bizancio

\begin{abstract}
This article analyses the process of translation and transmission of East Syrian martyr literature in the Eastern Roman Empire between V and VII centuries. The contexts in which these translations were produced, and their condition of circulation and reception are still insufficiently known. In order to shed light on this process, we will focus our analysis in one specific text, The Martyrdom of Zebinas and his companions, in order to explore the transmission of hagiographical topoi related to the Christian conception of royal authority, and the limits to the obedience due to pagan rulers. Our hypothesis is that the East-Syrian martyr stories that circulated in Byzantium underwent a complex process of adjustment that involved a wide range of strategies.
\end{abstract}

\section{Presentación y planteo del problema ${ }^{1}$}

En el Cercano Oriente tardo-antiguo coexistieron variadas tradiciones literarias en un complejo diálogo. Además del griego, el latín y el persa medio (lenguas de la cultura

\section{Keywords}

$\overline{\text { Martyrdom }}$ Christianity Late Antiquity Sasanian Empire Byzantium
1. Una porción de este trabajo fue presentada en las XVIII Jornadas de Bizancio, organizada por la Sociedad Española de Bizantinística Barcelona, 1 de febrero 2019. Quiero agradecer a Diego Santos por haber leído un borrador de este trabajo y por haber hecho valiosas sugerencias a él. 
2. Sobre las traducciones del siríaco al griego ver los trabajos de Paul Peeters (1922, pp. 252-257), Sebastian Brock (1977, 1998), Pablo Ubierna (2020b) y Anthony Kalldelis (2018).

3. Por Hechos siríacos de los Mártires persas nos referimos al heterogéneo conjunto de textos siríacos producidos en diversos contextos geográficos y cronológicos. En tal sentido, resulta muy difícil hacer una catalogación exacta de dichos textos por su proveniencia y la unidad de dicha literatura está dada (de una manera más o menos artificial) por su contextualización en el mundo iranio pre-islámico. Entre las principales ediciones de textos relativos a los mártires persas ver los trabajos de Hippolyte Delehaye $(1903,1907)$ y Paul Devos (1946; 1953-1954). Cf. Brock (2008, p. 91). Para las hagiografías conservadas en latín ver el trabajo de Christelle Jullien (2016).

4. Los textos conservados en siríaco triplican al menos esa cantidad.

5. Cf. Sozómeno, Historia Eclesiástica, II. 9-11 (Grillet \& Sabbah, 1983, pp. 266-293) y Teodoreto de Cirros, Historia Eclesiástica, V. 39 (Parmentier, 1911, pp. 342-347). cortesana y la administración respectivamente en Roma y en Persia) varias lenguas contaban con tradiciones literarias más o menos vitales: diversos dialectos del arameo y el copto, el armenio, el georgiano, el nubio antiguo y el etíope. Pero dicha coexistencia no debe entenderse como la mera superposición de tradiciones inconexas. Por el contrario, la diglosia era un fenómeno corriente y muchos de los intelectuales podían expresarse en más de un registro lingüístico. A menudo, la elección de una u otra lengua como forma de expresión era determinada por las adscripciones confesionales. Por ejemplo, con la imposición de la ortodoxia calcedoniana en el imperio romano desde la segunda mitad del siglo VI, la literatura miafisita expresada en lengua griega experimento un rápido declive mientras que el uso del siriaco, el armenio o el copto fue un marcador identitario para quienes se oponían a las decisiones del concilio. Paradójicamente, su desarrollo como lenguas literarias implicó cierto grado de helenización en su vocabulario y sintaxis.

De todas las tradiciones literarias del Cercano Oriente tardo-antiguo la más prolífica de todas fue sin duda la siríaca. El arameo (en sus varios dialectos) se había convertido en una de las lenguas literarias de cristianos, judíos y maniqueos desde el litoral mediterráneo hasta Jorasán. El siríaco (un dialecto particular del arameo originario de alta Mesopotamia y utilizado primariamente por los cristianos) coexistió con el griego como vehículo de transmisión intelectual por más de un milenio, y de esa coexistencia derivó un intenso movimiento de traducciones en uno y otro sentido. Aunque la corriente de traducción del griego al siríaco ha sido estudiada con bastante detalle (Brock, 1977; Ubierna, 2020a), el movimiento inverso ha recibido una atención menor $^{2}$. La mayor parte de los trabajos se ha centrado en la transmisión de teólogos (en particular Efrén de Nísibis e Isaac de Nínive), u obras hagiográficas, en especial los Hechos siríacos de los mártires persas ${ }^{3}$. De la veintena de historias de mártires persas conservados en la literatura bizantina ${ }^{4}$, menos de la mitad son traducciones completas. Una parte sustancial son epítomes incluidos en las Historias Eclesiásticas ${ }^{5}$ del siglo V o en el sinaxario constantinopolitano (Delehaye, 1902). Por otra parte, la gran mayoría de las versiones griegas corresponden a historias dedicadas a la "Gran persecución" bajo Sapor II (340-379) mientras que las historias de mártires de los siglos V al VII son comparativamente escasas. Este dato permite inferir que el movimiento de traducción alcanzó su mayor difusión entre mediados y finales del siglo V y que decayó en los siglos siguientes. Por último, el consenso académico ha ubicado el contexto geográfico de la mayor parte de las traducciones en ambos lados de la frontera romano-persa, ya sea en los grandes centros monásticos o en las metrópolis de Nísibis, Edesa y Maypherqat (Martirópolis) donde se encontraban importantes santuarios dedicados a los mártires persas. No obstante. no se puede descartar por completo un contexto constantinopolitano.

Una de las principales dificultades que encontramos al analizar los contenidos de la literatura martirial cristiana del imperio sasánida es la clasificación, contextualización y reconstrucción de los derroteros seguidos por cada uno de los textos, tarea que se vuelve imposible si tenemos en cuenta la deficiente tradición textual. En tal sentido, consideramos que el análisis de las formas y contenidos de las traducciones griegas pueden contribuir en nuestra comprensión de los procesos de producción-transmisión y recepción de los textos siríacos. Como primer paso en esa dirección, este trabajo se propone hacer un aporte al estudio de la relación entre las versiones griegas y siríacas de los Hechos siríacos de los mártires persas a partir de un objetivo general y dos objetivos específicos. El objetivo general es hacer una primera aproximación a la comparación de las formas y contenidos de algunas de las versiones siríacas y griegas conservadas de la literatura dedicada a los mártires cristianos en el Imperio sasánida. A partir de dicha comparación esperamos identificar las particularidades de los diversos estratos redaccionales. En cuanto a los objetivos específicos, por un lado, haremos un análisis comparativo de las versiones siríacas y griegas que puede aportarnos información acerca de su mal conocida historia textual. No es nuestra 
intención perseguir la quimera de una "versión original" ni identificar un contexto de producción preciso. Nos interesa la comparación de diversos estratos redaccionales para comprender la manera en que las tradiciones martiriales fueron transmitidas y apropiadas. El segundo objetivo se relaciona con el recorte elegido para comparar las versiones siríacas y sus traducciones griegas. Por un lado, nos limitaremos a comparar un tema específico, esto es, la relación entre adscripción religiosa y obediencia política a partir de los motivos y conceptos políticos desplegados en los diálogos entre los mártires y sus perseguidores. Por otro lado, y por razones de espacio, vamos a circunscribir nuestra comparación a un solo texto, el Martirio de Zebinas (BHO 531, $B H S$ 39, BHG 942-943) que es en buena medida un texto que sintetiza características contenidas en la mayoría de los martirios sirio-orientales.

\section{Las versiones del Martirio de Zebinas}

El Martirio de Zebinas está conservado en varias lenguas. La versión siríaca está contenida en cuatro manuscritos ${ }^{6}$ y es factible que el texto conservado sea la redacción original, aunque algunas inconsistencias en la narrativa pueden ser indicios de reescritura. Esta versión fue publicada junto con una traducción latina por primera vez en 1748 por el célebre estudioso maronita Esteban Evodio Assemani (ASM I, p. 215224), que usó como base el manuscrito conservado en la Biblioteca Vaticana. Paul Bedjan (AMS II, pp. 39-51) hizo una nueva publicación del texto en base al manuscrito actualmente conservado en la Staatsbibliothek de Berlín cotejado con el texto publicado por Assemani. Esta redacción siríaca nunca fue traducida íntegramente a una lengua moderna. François Lagrange (1852, pp. 21-29) realizó una traducción francesa parcial e inadecuada del texto latino de Assemani que fue reproducida en la compilación del benedictino belga Henri Leclercq (1902-1925, pp. 135-140).

Por su parte, las dos redacciones griegas están contenidas en dos manuscritos únicos. La primera redacción (BHG 942) -a la que designaremos A- es la más antigua y extensa y está contenida en el manuscrito de San Marcos de Venecia número 359 (fol. 99v-107) fechado entre los siglos $\mathrm{X} \mathrm{y} \mathrm{XI}^{7}$. El texto de la redacción griega A es el más próximo a la versión siríaca y fue publicado por primera vez por Hippolyte Delehaye (1903). El mismo Delehaye publicó una versión revisada del mismo texto junto con una traducción latina en el segundo volumen de la Patrologia Orientalis (Delehaye, 1907, pp. 421-436). La versión en eslavo antiguo conservada en el Codex Suprasliensis (127v-136v) es muy similar a esta redacción (Severianov, 1904, pp. 254-272). La redacción B (BHG 943) es un epítome de A y está contenida en el manuscrito de la biblioteca del santo Sínodo en Moscú 376 (fol. 247r-250v) del siglo XI. Esta versión fue publicada primero por Delehaye en la Patrologia Orientalis (1907, pp. 437-439), y luego por Vasili Latyshev (1911-1912, pp. 288-292). Además, de estas traducciones una versión abreviada fue incorporada al sinaxario de Constantinopla (Delehaye, 1902; ASM I, pp. 211-213). Del sinaxario bizantino se difundió al sinaxario armenio (Bayan, 1930, pp. 185-187) y al martirologio romano (29 de marzo) ${ }^{8}$. Por último, cabe destacar que -hasta donde hemos podido constatar- no se conserva una versión de este martirio en los sinaxarios árabes?.

\section{El autor y su contexto de producción}

Sólo podemos avanzar algunas hipótesis muy generales acerca de su autor, lugar y fecha de composición. No existen referencias externas que nos aporten información sobre estos mártires y los datos internos no nos permiten ir más allá de algunas vagas
6. BL Ms Add. 14654 (5v-8v) del siglo V o VI; Vat. Sir. 161 (fols. 82r-84v) del siglo IX; Ms. Berol. Or. Oct. 1256 (pp. 646-664) del siglo XIX que es una copia del manuscrito Diyarbakir 96 (conservado actualmente en Bagdad) del siglo XII o XIII; y el Manuscrito número 218 de la Biblioteca del monasterio de Nuestra señora de la simiente (Iraq) del siglo XIX. Para una noticia bibliográfica completa ver http://syriaca.org/work/26o y Fiey \& Conrad (2004, págs. 193-194).

7. Sobre este manuscrito ver Delehaye (1905, pp. 188-191) y Erhard (1937-1952, pp. 428).

8. Martirologium romanum, 159.

9. En efecto, no hay testimonios de esta historia ni en los sinaxarios melquitas conservados en el monasterio de Santa Catalina de Monte Sinaí ni en los sinaxarios maronitas o copto-árabes. 
10. i.e. originario de la región de Arzún en la frontera romano-persa. Cabe notar que el Vat. Sir. 161 dice "y arzanāyā". Sobre este personaje ver Barsoum (2003 [1956], p. 228) y Fiey \& Conrad (2004, p. 194).

11. Sir. men parāše dmalkā. Se trata además del heterograma que representa el persa medio aswār (Gignoux, 1972, p. 31).

12. Además, la referencia a Isaías como miembro de la caballería imperial permite asumir que su autor fue miembro de la baja aristocracia sasánida de la zona fronteriza con el Imperio romano por lo que debemos inferir una fecha relativamente tardía. En ese caso parece plausible que el texto refleje las condiciones en el que se produjo la progresiva cristianización de los estratos más bajos de la aristocracia persa en la segunda mitad del siglo $\mathrm{V}$, en especial aquellos establecidos como custodios de la frontera romana. Los llamados Dihqānān, o Dehqan, equivalentes a los limitanei bizantinos, soldados afincados en granjas en las zonas fronterizas, vinculados

al rey. Cf. Zakeri (1995, pp. 56-59) y

Christensen, (1944, pp. 112-113).

13. Es evidente que el nombre está corrompido y resulta imposible hacer una transcripción adecuada del nombre.

14. Sobre esta localidad ver Fiey (1963, p. 341) y

Wilmhurst (2000, p. 157)

15. Podemos especular que la caracterización de ambos como

"hermanos" no se refiere a una hermandad de sangre sino a la condición de "hermanos" en tanto monjes. Esta pareja de monjes, podemos especular, se nos presen-

ta muy similar a la adelphopoiesis descripta por Claudia Rapp (2016). Por otro lado, a lo largo del martirio hay vagas sugerencias del estatus clerical de ambos hermanos pero, como sucede en la mayor parte de la historia, su condición nunca es del todo explícita.

16. La “Gran persecución” de

Sapor II, que se inició con el arresto del arzobispo de Seleucia y Ctesifón Simeón bar Sabbatē y los miembros de su entorno, comenzó en algún momento entre los años 339 y 344 d. C., y la tradición la extiende hasta la misma muerte del monarca (379 d. C.). Sobre el debate en torno a su datación ver los trabajos de Timothy Barnes (1985), Richard Burgess (1999) y en especial la síntesis de Kyle Smith (2014, pp. xx-xxiv). especulaciones. Tanto Paul Devos (1966, p. 224) como J. M. Fiey (2004, p. 194) consideraron que era una historia puramente legendaria y no se preocuparon por sugerir un lugar o fecha de composición. El manuscrito más antiguo (BL Add. 14654) está fechado entre los siglos V y VI y marca el terminus ante quem de su redacción. La autoría es atribuida por el texto mismo a un supuesto testigo de los eventos, Isaías bar Hadbō o Hadābhū el arzunita ${ }^{10}$ descripto como "de los caballeros del rey" (AMS II, p. 51). Esta atribución, aunque posiblemente guarde cierto núcleo de historicidad, es cronológicamente inconsistente. En efecto, si el autor fue además testigo presencial de los eventos deberíamos considerar que vivió en la primera mitad del siglo IV. Esta cronología resulta difícil de aceptar dado que -según el consenso académico- los primeros textos de la literatura martirial sirio-oriental fueron compuestos recién en las últimas décadas del siglo IV o las primeras del siglo V (Smith, 2014, p. xxiii). Asimismo, las coincidencias tanto de contenidos como formales con otros textos compuestos en la segunda mitad del siglo V sugiere una datación que no puede ser anterior al $450 \mathrm{~d}$. C. ${ }^{12}$

Los topónimos tampoco ofrecen demasiados datos de relevancia. No existe ninguna referencia a un santuario dedicado a la memoria de los mártires que nos permita ubicar una localidad específica. La aldea de la que eran originarios Jonás y su hermano -que en siríaco se transcribe $D H W B H^{13}$ y en griego $\beta a \rho \delta \mathrm{s} \alpha \hat{\omega} \mathrm{x}$ - no puede identificarse con ningún otro lugar conocido. Por otro lado, la aldea de Bēth Asā donde fueron martirizados puede coincidir con la localidad homónima en la región de Maragā, al Este del Tigris, pero esta identificación es apenas una especulación ${ }^{14}$. Por último, el uso del calendario lunar (Mercier, 1999; Stern, 2004) en el colofón del texto sugiere que el contexto de producción más probable fue el Imperio sasánida pero resulta imposible avanzar más allá de dicha constatación. En suma, podemos sugerir con cierto grado de certeza que el Martirio de Zebinas fue compuesto en algún lugar del Iraq sasánida, cerca de la frontera romano-persa por un miembro de la elite cristiana sirio-parlante local entre finales del siglo V y (si extendemos la fecha del manuscrito londinense) principios del VI.

\section{El Martirio de Zebinas: temas y contenidos}

Antes de comparar las versiones siríaca y griega debemos hacer un breve sumario del texto. Los personajes centrales de la historia son dos "hermanos" (probablemente monjes ${ }^{15}$ ) llamados Jonás y Brīkhīšō (o ßapaxioııs en la versión griega) que, de acuerdo con la historia, fueron martirizados en algún lugar de la alta Mesopotamia persa en el año dieciocho del reinado de Sapor II (327 d. C.), varios años antes que diera comienzo la "Gran persecución". Los hermanos visitaron a otros nueve cristianos (el mártir Zebinas y sus ocho compañeros) que habían sido encarcelados por las autoridades persas para forzarlos a realizar los sacrificios "al fuego, el sol y el agua" (AMS II, p. 40). En dicha visita, los hermanos "los alentaron e instruyeron con las escrituras y los fortificaron para que unos sean confesores y otros sean coronados por la espada de la persecución"16 (AMS II, p. 40). Luego de la ejecución de los nueve mártires, los hermanos fueron también encarcelados acusados de instigar a sus compañeros. Después de varias e infructuosas sesiones que combinaban interrogatorios y torturas, fueron ejecutados y sus cadáveres arrojados a la intemperie para luego ser rescatados por los fieles.

El Martirio de Zebinas está estructurado en una secuencia de siete partes. Una introducción que contextualiza la narrativa, seguida de cinco "diálogos" más o menos extensos en los que los mártires polemizan alternativamente con sus perseguidores. El texto finaliza con una descripción de la ejecución de los santos junto con el 
"rescate" y ocultamiento de sus cuerpos. Cada uno de los diálogos se conecta con el anterior y guarda una estructura similar: los santos responden a los requerimientos de sus antagonistas (invariablemente la exigencia de sacrificar a los elementos) con argumentaciones doctrinales, apoyadas en parábolas y cadenas de citas bíblicas. La estructura general de los diálogos se puede sintetizar de la siguiente manera:

\begin{tabular}{|c|c|c|c|c|c|}
\hline & \multicolumn{2}{|c|}{ Versión siríaca } & \multicolumn{2}{|c|}{ Versión griega $(A)$} & \multirow{2}{*}{ Temas } \\
\hline & Protagonista & Antagonista & Protagonista & Antagonista & \\
\hline 1 & $\begin{array}{l}\text { Jonás y } \\
\text { Brīkhīšōoc }\end{array}$ & Juez del rey & $\begin{array}{l}\text { Jonás y } \\
\text { Barakhisios }\end{array}$ & \multirow[t]{5}{*}{$\begin{array}{l}\text { Tres } \\
\text { ápxı́áyoı: } \\
\text { Masdrath, } \\
\text { Sêrôth y } \\
\text { Maarnêsí }\end{array}$} & $\begin{array}{l}\text { La supremacía de } \\
\text { Dios sobre el rey y el } \\
\text { origen de la autoridad } \\
\text { política. }\end{array}$ \\
\hline 2 & Jonás & \multirow{4}{*}{$\begin{array}{l}\text { Dos rabay } \\
\text { mgūšēe: } \\
\text { Hōrmīzd- } \\
\text { 'ardāšîry } \\
\text { Mïharnarsay }\end{array}$} & Jonás & & $\begin{array}{l}\text { La apostasía y la } \\
\text { obediencia al rey. }\end{array}$ \\
\hline 3 & Brīkhiššōc & & Barakhisios & & $\begin{array}{l}\text { La oposición entre el } \\
\text { culto a los elementos } \\
\text { y el culto a Dios. }\end{array}$ \\
\hline 4 & Jonás & & Jonás & & $\begin{array}{l}\text { Cristo es la verdadera } \\
\text { salvación. La } \\
\text { autoridad de las } \\
\text { escrituras. }\end{array}$ \\
\hline 5 & Brīkhīšōc & & Barakhisios & & $\begin{array}{l}\text { La restauración } \\
\text { del cuerpo de los } \\
\text { mártires por parte de } \\
\text { Dios. }\end{array}$ \\
\hline
\end{tabular}

La distribución de los diálogos en el Martirio de Zebinas.

En cada uno de los diálogos, la victoria del santo es seguida por sesiones de tortura que reflejan la incapacidad de los antagonistas por doblegarlo. En el cuadro constatamos que el autor desarrolló diferentes topoi de la literatura martirial. Todos ellos tienen en común la tensión entre la obediencia al monarca y la fe cristiana. Mediante estos diálogos ficticios el autor perseguía un objetivo primariamente pedagógico, esto es, definir una identidad cristiana basada en el monoteísmo estricto, el ascetismo y la obediencia a las escrituras.

La versión griega (A) sigue casi con exactitud cada una de las escenas de la versión siríaca. No obstante, existen sustanciales diferencias que reflejan un proceso de transmisión complejo, cuyos detalles concretos desconocemos. Dos momentos de la secuencia de diálogos resultan significativos ya que pueden ayudarnos a entender las lógicas puestas en juego en el proceso de traducción. El primero corresponde a la primera escena en la que (en la versión siríaca) los hermanos comparecen juntos ante el juez real (diálogo 1). La escena está dividida en dos partes. En la primera, la acusación contra los santos es leída ante el juez. Como ya hemos señalado, los hermanos son llevados ante el tribunal acusados de instigar a otros cristianos al martirio. Sin embargo, el juez no se preocupa por determinar la veracidad de la acusación sino que se limita a exigir un gesto de sumisión religiosa y política a través de la conformidad con los ritos zoroastrianos. El hagiógrafo pone en boca del magistrado la siguiente amenaza:

Les juro por la buena fortuna (gadă) del rey de reyes, el mejor los hombres (țabā dgabrē), que no me engañarán. ¿Obedecerán la voluntad del rey de reyes, bendecirán y adorarán al sol y al fuego y al agua, y los honrarán como es la ley que tienen los reyes de nuestra tierra? (AMS II, p. 41). 
17. Cf. el uso de gadā en el contexto bíblico: Gn. 30: 11; Is. 65: 11. Por su parte, Menandro Protector, (Excerpta de legationibus, II, 16) hace referencia a este concepto en la ideología imperial sasánida. Notemos además que en la escritura pahlavi el heterograma $G D H$ era la forma usual para expresar el término persa medio xwarrah. Ver Bailey (1943, págs. 1-51), Gnoli (1999), Soudavar (2003),

Panaino, (2007) y Daryaee (2008).

18. Por ejemplo, en el discurso de Pablo el persa ante Cosroes I (Land, 1875, pág. 1).

19. Para una primera aproximación al tema del vocabulario político sasánida ver también los trabajos de Bailey (1943), Widengren (1959) y Choksy (1988).

20. Cabe notar que entre las invocaciones del juez no encontramos una de las nociones más potentes del vocabulario político sasánida, esto es, la asociación del monarca con la divinidad (pero muy lejos de una divinización) contenida en el expresión "cuya familia (proviene) de los dioses"

(kē čihr az yazadān). Esta expresión es reelaborada en los textos martiriales siríacos como "de la simiente de los dioses" (men za 'rā dalāhē). Cf. AMS II, 53 (Sundermann, 1988; Daryaee, 2008, pp. 65-68).
En las palabras del juez se encuentran tres elementos característicos de las expresiones de legitimidad real sasánida. El primero de ellos es el concepto de "buena fortuna" expresado en el término siríaco gadā. Este término es equivalente al griego túxๆ y al persa medio $x w a r r a h^{17}$. El segundo, es la expresión "el mejor de los hombres" que se encuentra atestiguada para el protocolo cortesano ${ }^{18}$. El tercer elemento se encuentra en la expresión de "la ley que tienen los reyes de nuestra tierra". Esta proclamación de la territorialidad de las leyes del Rey de reyes no es un mero formulismo, sino que proclama la íntima relación entre adscripción política, identidad religiosa y territorio. En este sentido, las palabras del magistrado pueden ser entendidas como una alusión a la noción de Erānšăhr "el país de los iranios" como unidad político/religiosa destinada al dominio universal.

No vamos a profundizar en el análisis de estas tres expresiones que ya han sido objeto de estudio por parte de Antonio Panaino (2007) y Turaj Daryaee (2008) entre otros ${ }^{19}$. En cambio, queremos enfocarnos en la manera en que el hagiógrafo contrapone dichos elementos con sus propias nociones (cristianas) sobre el origen del poder político. Como dijimos, al poner en boca del juez estas tres exclamaciones el hagiógrafo enuncia nociones de la "teología política" sasánida que proclamaba la naturaleza universal y carismática del monarca quien -aun reconociéndose como humano ${ }^{20}$ - era un кобнокра́ $\omega \rho$. A primera vista, las aclamaciones puestas por el hagiógrafo en la boca del magistrado constituyen una fiel reproducción de conceptos reconocibles por los súbditos del rey de reyes. Sin embargo, este vocabulario no es exclusivo de las composiciones sirio-orientales sino que -como veremos- también pueden encontrarse en las versiones siríacas de los martirios griegos. De esta manera, podemos interrogarnos si las palabras constituyen una particularidad de los martirios cristianos del imperio sasánida o si, por el contrario, se trata de la inscripción de aquellos en una reconocida tradición literaria.

La respuesta a este interrogante no es definitiva, pero el desarrollo del diálogo presenta algunas claves en ese sentido. Como en muchos martirios occidentales, el hagiógrafo estructura el antagonismo entre la identidad cristiana y la obediencia al rey en torno al sacrificio. Sin embargo, para el autor del Martirio de Zebinas el rechazo a participar en ellos no implicaba el rechazo a la autoridad del monarca. Por el contrario, dicho rechazo establecía una jerarquía en la que el sacrificio era un límite a la obediencia debida. Como sugieren otros textos hagiográficos contemporáneos -por ejemplo, el caso del eunuco Guštazad en el Martirio de Simeón Bar Sabba'é(Smith, 2014, pp. 38-44, 109-120), o los Hechos de Mār Māri (Jullien \& Jullien, 2003, pp. 32-35(T); 37-39(V))- la eventual participación en los rituales religiosos paganos era, para las elites cristianas, una tentación difícil de resistir dada su importancia para incorporarse a las redes de solidaridad social tanto locales como aquellas vinculadas a la corte. En tal sentido, debemos notar que la participación en los sacrificios en el marco de una religiosidad que distaba de ser exclusiva y contemplaba la integración jerarquizada de diversas formas cultuales no resultaba (al menos desde el punto de vista de la monarquía) contradictoria. Dicho de otra manera, desde el punto de vista de la monarquía la resistencia de algunos (pero no todos) cristianos a participar de los ritos de consenso político resultaba incomprensible.

Es precisamente contra la participación de los cristianos en los ritos de consenso político que el autor lanza su diatriba. Los mártires responden a la interpelación del juez cuestionando los fundamentos mismos de su autoridad:

Pues no es este rey el que te dio esta autoridad al que te conviene temer, sino al que te dio sabiduría y conocimiento. Pues te conviene reconocer al que es rey de reyes y señor de la tierra y el cielo, y que fija los tiempos y cambia las estaciones y da sabiduría a los sabios para que dicten sentencia y que ejerzan la autoridad 
sobre sus semejantes con la verdad. Y te pedimos que nos digas, ¿a cuál rey (laynā malkā) estamos obligados a obedecer nosotros los hombres? ¿Al que-dijimos-que hizo todas las cosas? ¿O al rey mortal (Imalkā dmāet) y que será sepultado con sus padres? (AMS II, 41-42).

El fragmento pone en primer plano el problema de la obediencia debida al monarca, contrastada con aquella debida a Dios. Esta oposición es un lugar común frecuentemente aludido en la literatura martirial. Uno de los primeros testimonios de dicho tema se encuentra en el Martirio de Policarpo de Esmirna (BHG 1556 y ss., BHL 6872 y ss., $B H O$ 998) donde el magistrado encargado del juicio le exige al santo jurar por la "buena fortuna del César" (Gr. Túxๆ, Lat. fortuna, Sir. gadā) y el mártir responde con una paráfrasis de Rom. 13: 1 reconociendo la obligación de todo cristiano a honrar ${ }^{21}$

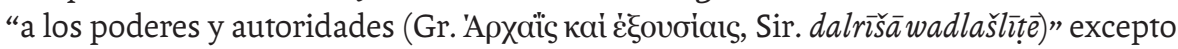
que estos exijan violar el mandato divino ${ }^{22}$. La consecuencia de la actitud de Policarpo es la resistencia pasiva y la admisión voluntaria de la muerte en la arena. De esta manera, el autor de la historia fija una tradición en torno a los límites de la obediencia y la desobediencia política que se haría dominante en la literatura martirial. Dicha tradición sanciona la sumisión a las autoridades como una obligación de todo cristiano, al mismo tiempo que habilita la resistencia pasiva que eventualmente podía llevar a la muerte. Este motivo se presenta bajo numerosas variantes. Por ejemplo, en la Historia de Simeón bar Sabba'é el obispo justifica su desobediencia (recaudar un doble impuesto a los cristianos) señalando que "nuestra autoridad es celeste y no proviene de los reyes del mundo" (Smith, 2014, p. 85). Por su parte, en el Martirio de Pōsi el santo se niega a obedecer la voluntad de Sapor (de adorar los elementos) reconociendo su "autoridad sobre los seres vivos corporales" pero no sobre su alma (AMS II, 223). En el Martirio de Pêrōz (BHO 921) el mártir responde la requisitoria del rey con una pregunta acerca de las prioridades en la obediencia:

El victorioso (Pērōz) dijo: “¿Conviene obedecer a Dios más que a los seres humanos, o a los seres humanos más que a Dios?" El rey dijo: "Debe obedecerse a Dios". El victorioso dijo: "Si conviene obedecer a Dios, escúchame, Dios es uno y no se lo debe cambiar por otra cosa, como se nos ha ordenado" (AMS IV, pp. 259-260).

En los tres casos, la desobediencia al rey se sustenta en la imposibilidad de obedecer una ley temporal o corporal que contradice las leyes espirituales prescriptas por Dios. En cambio, la respuesta de los mártires en el Martirio de Zebinas parte de fundamentos sensiblemente diferentes. En lugar de la simple contraposición entre la obediencia a las leyes divinas y la obediencia a un monarca mundano, ella alude a una antropología que concibe a la razón como atributo divino conferido al ser humano. Así el mártir afirma que la autoridad (šulttanna $)$ del magistrado no deriva de la delegación del rey/ mortal sino del rey/Dios que le ha dado "sabiduría y conocimiento" y "da sabiduría a los sabios". Estas expresiones no son afirmaciones casuales. Por el contrario, ellas aluden a una tradición sapiencial presente a lo largo del Antiguo Testamento en la que Dios es señalado como fuente y garante del buen gobierno a través de la razón. En dicha tradición, términos como sabiduría (Gr. oopia sir. hekmtha), conocimiento

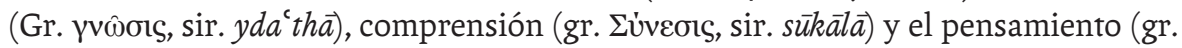
Évvola, sir. tarîtha ) definen atributos divinos conferidos a los seres humanos en general y a los gobernantes en particular ${ }^{23}$. En suma, las palabras de los mártires no se orientan a la simple distinción entre la esfera mundana y la esfera espiritual sino a la moralización acerca del ejercicio del poder bajo la guía de Dios, fuente última de autoridad política ${ }^{24}$.

A partir de esta definición de la autoridad política, el autor jerarquiza la monarquía humana y la monarquía universal del Dios cristiano, el verdadero rey de reyes eterno que ejerce su dominio sobre la naturaleza (en otras palabras, es el verdadero
21. Clark, 1991. Nótese que tanto en la versión siríaca como la griega la idea de una obediencia de Rom. 13: 1 es reemplazada por el honor.

22. Las versiones siríaca (AMS VI, p. 62), griega (Musurillo, 1972, p. 10) y latina (Ruiz Bueno, 1951, p. 272) difieren sensiblemente en este pasaje. No obstante, en los tres se mantiene el sentido general (Lendon, 2001).

23. En 1 Chr. 22:12 David revela a Salomón la voluntad divina para su reino dice "y que el Señor te de sabiduría y comprensión”. Otro ejemplo significativo es el pasaje del libro de los Proverbios (2: 6) que dice "Pues el Señor da la sabiduría y de su boca (viene) el conocimiento y el entendimiento". Este topos se repite en numerosas oportunidades, Cf. Deut. 4: 6;

Prov. 1: $7 ; 9: 10 ; 13: 15 ; 23: 23$; 24: 7; Job: 12:13, 16; 4 Mac. 1: 16; Ps. 73: 11; 111: 10; Eccl. 9: 10; 2 Ch. 2: 11; Is. 11: 2; Si. 1: 4; Dan 2: 20.

24. Por otro lado, el vocabulario presenta ecos a una antropología de inspiración aristotélica (que tiene paralelos en otros filósofos sirio-orientales como Pablo el persa y Ahūdemmēh) basada en la razón como atributo divino insuflado en el alma humana (Hugonnard-Roche, 2014). 
25. i.e. al fuego, en siríaco, el sustantivo nūrā "fuego" es femenino. кобнокра́ $\omega \rho)$ y al que los magistrados deben obediencia en tanto sus criaturas. Otros martirios compuestos en la segunda mitad del siglo $\mathrm{V}$ reproducen ideas similares. En el Martirio de Narsay ( $\mathrm{BHO} 786$ ) se desarrolla un motivo que tiene numerosos puntos de contacto. En este caso, el mártir responde a la requisitoria del Mowbed Ādūrbōzē de adorar a los elementos con las siguientes palabras:

[dice Ādūrbōzē] “¿Cómo actúas con esa audacia y no temiste y entraste al templo del fuego y la la apagaste y destruiste el altar en el que ella estaba, y no temiste el juicio del rey?” Y el bienaventurado Narsay le respondió diciendo: “Entonces ¿a quién se debe temer, al Dios que dio la diadema al rey y cuya autoridad es sobre toda la creación, o al rey transitorio que hoy existe y mañana entrega su reino a otro?" (AMS II, p. 173; Herman, 2016, p. 9).

Si bien no son completamente coincidentes, los dos fragmentos reflejan un argumento común. Tanto Jonás y Brīkhīšōo como Narsay sustentan su desobediencia no solo en la superioridad del temor de Dios -es decir la fe cristiana (Becker, 2009)- sobre el temor a las leyes del rey, sino que, además, desafían dos conceptos fundamentales de la ideología imperial, esto es, la eternidad y la naturaleza cósmica de la monarquía irania. En otras palabras, el "reino de Dios" al que aluden los mártires no es tanto el reino espiritual de Juan 18: 36-37 (perteneciente a un ع̌ $\sigma x \alpha \tau o \varsigma$ ubicado en un futuro indeterminado) como la verdadera monarquía cósmica (en el aquí y ahora) que confiere una indiscutible autoridad y a la que todos los hombres -incluso los reyes-deben someterse.

En el caso del Martirio de Zebinas la naturaleza de la autoridad real vuelve a ser discutida en el tercer diálogo. En este caso, los magos retoman la fórmula "por la fortuna del rey de reyes" durante la ordalía a la que es sometido Brīkhīšóc. En la escena, los magos colocan dos esferas de hierro ardiente en sus axilas diciendo: "Verdaderamente, por la buena fortuna del rey de reyes que si dejas caer una de ellas a la tierra habrás negado" (AMS II, p. 46). Nuevamente, la fórmula es una invocación a la autoridad real que precede la realización de un acto ritual/judicial (una ordalía) en el contexto del proceso contra los mártires. En este caso, la ordalía es equivalente al interrogatorio de la escena anterior en la medida que ambas acciones están dirigidas a determinar la verdad bajo la autoridad cósmica del rey. La respuesta de Brīkhīšó desarrolla un lugar común de la literatura martirial, esto es, la resistencia del mártir a las torturas en virtud de la gracia de Dios y de las recompensas prometidas en el mundo venidero:

¡Sirvientes de Satán el rey impío! (mšamšānāw dsātāanāmalkā raš̌ de nuestro señor Jesucristo hijo de Dios, no temeré a vuestro fuego, y no dejaré caer a tierra ninguna de sus esferas. [...] Pues es justo para el que va a la guerra por Dios que participe en la competencia virilmente. En especial aquel que recibe de Dios un mejor regalo y hereda un grado de honor. (AMS II, p. 46).

No es nuestra intención tanto profundizar en este bien conocido topos hagiográfico como señalar la simetría que existe entre las fórmulas empleadas por perseguidores y perseguidos. En primer lugar, notemos que el equívoco epíteto "Satán el rey impío" tiene, tanto para el autor como para su eventual audiencia, una evidente resonancia política. Encontramos la misma expresión en un texto martirial más o menos contemporáneo, el Martirio de Babhōy (BHO 126), Católico de la Iglesia de Oriente (457-484), en el que el obispo es acusado de alta traición por utilizar la expresión "Dios nos ha confiado a un reino impío" en una carta dirigida a un correspondiente indeterminado en el Imperio romano (AMS II, p. 632). Por supuesto, es imposible de verificar la existencia de un vínculo directo entre ambos textos pero la coincidencia lexical es sugerente. En tal sentido, nos sentimos inclinados a pensar que la recurrencia de la misma expresión es un indicio firme de la difusión de un vocabulario político en el 
que la exégesis del libro deuterocanónico de Daniel (en especial 3: 32) servía como marco conceptual en la reflexión en torno a la relación entre los cristianos y la monarquía pagana. En el caso del Martirio de Babhōy el autor se esfuerza por señalar que el epíteto impío no es denigratorio de la monarquía sino que significa simplemente "no cristiano" (AMS II, p. 634). Por su parte, el autor del Martirio de Zebinas hace referencia directa al "rey impío" como una condena moral pero con una prudente ambigüedad en torno a la identidad del rey (¿Sapor o Satán?).

En segundo lugar, la invocación que introduce el desafío del mártir: "por la salvación de nuestro señor Jesucristo hijo de Dios" guarda una evidente simetría con la invocación a la "buena fortuna" del rey. Como en el caso anterior, el hagiógrafo construye la narrativa a partir de un mecanismo de inversión. Si el valor de verdad de la ordalía descansa en la buena fortuna del rey -y su dominio sobre el elemento fuego- la victoria del santo se asienta en una fuerza superior, esto es "la salvación en Cristo", y las superiores recompensas dispuestas por este (como verdadero rey de reyes). La simetría se refuerza en un vocabulario que evoca las distinciones conferidas por el rey en la corte. La evocación se desprende de la equiparación de la recompensa en el reino venidero con los "grados de honor" y un "regalo" que identificamos como términos con una potente carga semántica dentro de la literatura martirial. Muchos martirios señalan los regalos ofrecidos por el rey a cambio del sacrificio y la apostasía como la expresión material del ascenso social que derivaba de la conformidad con la religión del rey. Dicha expresión material no se reduce a la promesa de una riqueza en términos exclusivamente económicos sino que, además, desde el plano simbólico esos regalos (vestimentas, joyas y otros bienes muebles) representaban el vínculo de obediencia y lealtad entre el rey y su súbdito. En este caso, los regalos y honores espirituales prometidos por el verdadero rey, señala el autor, son superiores a cualquier promesa del rey terrenal.

En suma, el autor utilizó el vocabulario político sasánida como parte de un discurso polémico que señalaba la superioridad de la monarquía del dios cristiano por sobre la monarquía terrena. En tal sentido, este contesta las pretensiones de una naturaleza cósmica y sagrada de la monarquía al mismo tiempo que instituye a los mártires como vehículos del poder divino. ¿Podemos afirmar una hostilidad hacia la monarquía? No necesariamente, más allá de la condena moral dirigida al rey de reyes como un individuo, el autor del Martirio de Zebinas no es hostil a la monarquía sasánida en tanto institución. En el caso del primer diálogo, en el que el antagonista es el juez, el tono relativamente moderado revela una intención de encontrar equilibrio entre identidad religiosa y obediencia política. El juez es interpelado en tanto magistrado de una monarquía cuya legitimidad deriva de la voluntad Dios. Por el contrario, los Mowbeds constituyen el verdadero foco de la hostilidad del hagiógrafo quien los identifica como rivales del clero cristiano en tanto son decodificados por la narrativa como una forma alternativa de "especialistas en lo sagrado".

\section{La redacción griega del Martirio de Zebinas}

Veamos ahora la manera en que la versión griega (A) presenta las mismas escenas. Como ya hemos señalado, en el primer caso la versión griega reproduce en lo esencial la versión siríaca. Sin embargo, la traducción dista de ser literal. En la versión griega los Mowbeds (que ocupan el lugar que ocupa el juez en la versión siríaca) dicen:

Les exigimos por el invencible (ánttńtou) rey de reyes Sabor que nos respondan sin mentiras de aquello sobre lo que les ha sido requerido por nosotros, ¿Harán la voluntad del rey y obedecerán su orden y adorarán al sol, al fuego y al agua de acuerdo a la ley y decreto de nuestro rey o no? (Martirio de Jonás (A), p. 23) 
26. PSI 1, 76" "Y te exijo (દ́vopkû), por la santa y consubstancial trinidad y por la victoria y permanencia de nuestros invencibles (ánttít $\omega v$ ) y muy piadosos Señores, Flavio Justino el eterno Augusto mayor benefactor y emperador y Elia

Sofía nuestra muy piadosa Señora, que no salgas de [la ciudad] de los alejandrinos [...]". Cf. De Jong (2006, pp. 99-102). Nótese la coincidencia en el verbo que encabeza

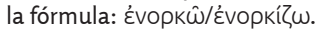

En el fragmento identificamos dos variantes significativas con respecto a la versión siríaca. En primer lugar, el juez ha desaparecido y en su lugar toman la palabra los Mowbeds como sujeto colectivo. En segundo lugar, las elaboradas fórmulas de la ideología imperial sasánida son reemplazadas por la fórmula "Por el invencible rey de reyes

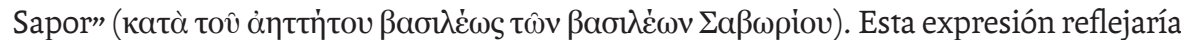
cierta equivalencia con la forma siríaca bgadèh dmelekh malkèt țaba dgabrēh, en tanto ambas invocan la naturaleza carismática de la autoridad imperial. Pero la estrategia de

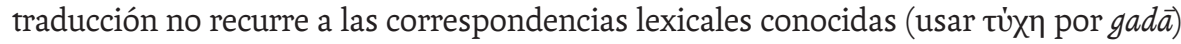
ni a buscar equivalencias de significados. En su lugar la versión griega introduce un

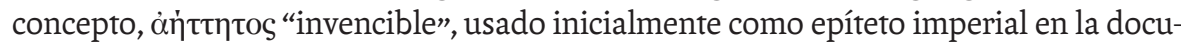
mentación administrativa de Egipto bajo la dinastía de los Severos, e irregularmente atestiguado en los siglos IV y VI. De los testimonios uno de los más interesantes es un papiro griego (proveniente de Egipto) fechado entre 572 y 573 conteniendo una fórmula de juramento en un proceso judicial ${ }^{26}$. No podemos afirmar que el uso del epíteto

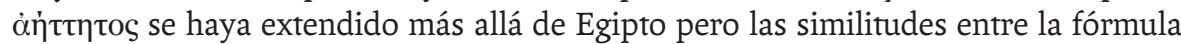
presente en el papiro y la versión griega del Martirio de Zebinas son lo suficientemente significativas como para postular como hipótesis que el traductor privilegió una fórmula inteligible en un contexto romano/cristiano. En otras palabras, en lugar de realizar una traducción palabra por palabra o buscar equivalentes en el significado, el autor reelaboró una traducción para que sea inteligible a su eventual audiencia.

La respuesta que los mártires dirigen a los magos presenta desplazamientos similares:

¿No deben temer más que al rey terrenal (દ́nıүદíoc) a aquel que les dio sabiduría y conocimiento y reconocer al Dios que tiene la autoridad sobre el cielo y la tierra y toda alma, que distingue y administra las estaciones, y les da sabiduría y concede la prudencia para que juzguen con prudencia a aquellos que en la carne son semejantes a ustedes? Entonces les requerimos que nos respondan en fe y en verdad: ¿A qué Dios

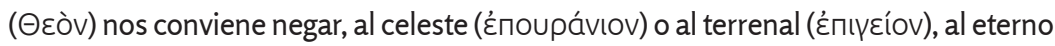

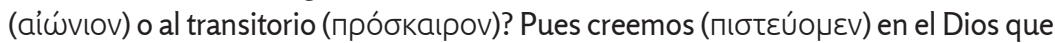

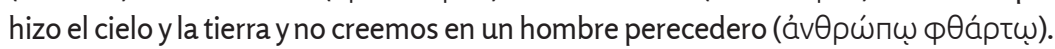

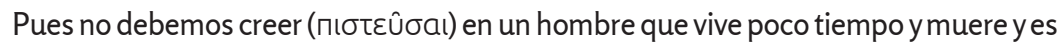
enterrado como nosotros y es incluido entre sus hombres. (Martirio de Jonás (A), p. 24).

Comprobamos en el fragmento que la traducción griega no solo reelabora sino que además amplía los contenidos de la versión siríaca a partir de un nuevo marco conceptual

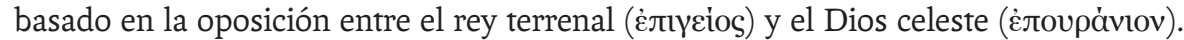
Pero mucho más notable es el desplazamiento de sentido al reproducir la parte final de la declaración. Mientras que en la versión siríaca los mártires desafían al juez preguntando ¿a cuál rey debemos resistir nosotros los hombres? en la versión griega los mártires se interrogan "¿A qué dios nos conviene negar?" para señalar de inmediato que

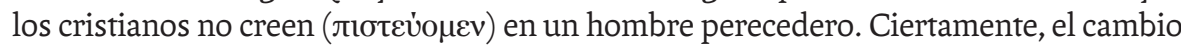
resulta significativo y no puede atribuirse a un simple error o a una tradición textual

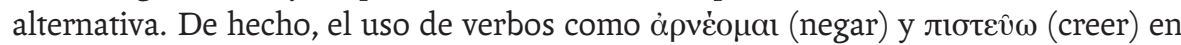
donde la versión siríaca usa šmac (escuchar, obedecer) reflejan un uso creativo de las equivalencias para desplazar al monarca del campo de la obediencia al de objeto de culto (en reemplazo de los elementos). En suma, las elecciones lexicales de la traducción no parecen fortuitas. Por el contrario, podemos señalar una lógica concreta que incorpora un motivo conocido en la literatura anti-persa de los siglos V al VII, esto es, acusar al monarca iranio de arrogarse una naturaleza divina (Panaino, 2007, pp. 559-575).

Veamos ahora el segundo fragmento analizado. Si en el primer discurso la traducción procede a través de la omisión y el reemplazo de fórmulas sasánidas por elementos reconocibles del vocabulario jurídico bizantino y la literatura anti-persa, en el segundo caso la traducción griega reproduce el vocabulario de la versión siríaca haciendo una 
elección lexical particular. En este caso, el término siríaco gadā no es omitido sino

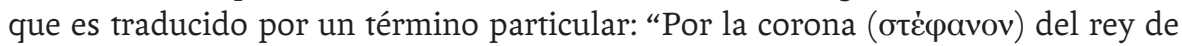
reyes Sabor si sueltas de tu axila uno de los bultos ardientes y cae al suelo, como sabrás, sabremos verdaderamente que has negado a tu Dios" (Martirio de Jonás (A), p. 29). A diferencia del fragmento anterior, la exclamación de los magos que precede a la ordalía no elimina el concepto sino que lo traduce con el término otغ̇ழavos. No existe ningún antecedente para tal elección pero ella no resulta descabellada. El término otépavos alude tanto a la corona nupcial como la obtenida en la competencia atlética, dos conceptos que forman parte del vocabulario martirial. Y, si bien el uso de este sustantivo para referirse a la corona imperial es poco frecuente, no es completamente extraño ${ }^{27}$. Por lo tanto, podemos sugerir como hipótesis que el uso de otéçavos como traducción de gadā supone una lógica creativa en la que la corona del rey de reyes (cuya simbología cósmica era bien conocida en el mundo bizantino) es presentada como símbolo de su autoridad y a la vez como contraparte de la corona del martirio. La validez de esta analogía queda confirmada por la respuesta del santo Barakhisios:

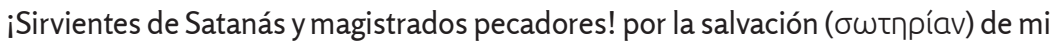
Dios y la perdición de Satanás vuestro padre, no temeré a vuestro Dios ni dejaré caer uno de esos bultos al suelo sino que por el nombre de mi Cristo los gobernaré [...] ¿ Pues quién va a la competencia de la guerra e ingresa al combate y no se rinde voluntariamente a la muerte para recibir un gran nombre y muchos dones por parte del rey y heredar un lugar principal? (Martirio de Jonás (A), p. 30).

En este pasaje la versión griega presenta dos características significativas. Por un lado, a diferencia de la versión siríaca que dice “iMinistros de Satán el rey impío!” (mšamšānāw dsātāna àmalkāraší $\vec{a}$ ), presenta una forma más atenuada: " $i$ Sirvientes de Satanás y magis-

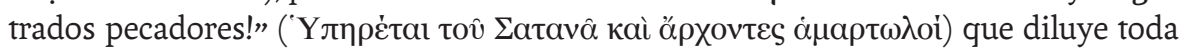
referencia a la monarquía. Por otro lado, la traducción griega no reproduce fielmente la

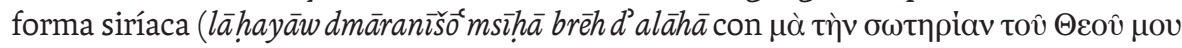

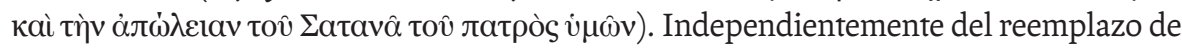
Cristo por Dios, la cláusula $\mu \grave{\alpha}$, introduce tanto la exclamación de los magos como la del santo dando simetría a la escena e instituyendo la victoria del mártir como el reflejo de la victoria de Dios sobre Satanás. Así podemos entender la lógica del traductor, la corona del rey (símbolo de su victoria) es contrapuesta a la salvación ( $\sigma \omega t \eta \rho i \alpha)$ en Dios que confiere la victoria al mártir sobre Satanás.

En suma, la traducción griega procede a partir de una batería de recursos que adaptan la versión siríaca a un público diferente. Ya sea por la omisión, el recurso a equivalentes gramaticales, la búsqueda de equivalentes conceptuales o el reemplazo por nuevos sentidos, la versión griega tiende a estandarizar las particularidades del texto siríaco. De esta manera, elementos ausentes en aquella (la oposición entre la monarquía terrenal y la monarquía celeste, la deificación del rey) emergen en una nueva versión adaptada a un canon de temas propios de la literatura de mártires griega.

\section{Conclusión}

Para concluir, este ejemplo nos presenta una constante en las estrategias de traducción en la Antigüedad tardía: la tensión entre una traducción orientada hacia el texto, es decir, la búsqueda de equivalentes gramaticales para respetar el original y la traducción "libre" orientada al lector, y sacrificando el texto por un sentido significativo para la audiencia (Brock, 1977). El proceso de traducción emerge así como algo dinámico en el que los aspectos catequéticos priman por sobre la fidelidad a un texto
27. Por ejemplo, Juan Crisóstomo aludía a la corona real en relación a la cruz: (PG 48, col. 826)

"Ninguna corona real adorna la cabeza como la corona que es más digna de honor que el mundo". 
determinado. En tal sentido, quien haya sido el traductor estaba más preocupado por el valor moral de la historia que por la exactitud de los conceptos. La versión siríaca y la versión griega del Martirio de Zebinas son dos momentos específicos en el proceso de transmisión de la historia. La primera presenta muchos de los rasgos característicos de los martirios sirio-orientales. Su objeto era promover el culto a los mártires vinculado a la elite cristiana sirio-parlante local y, al mismo tiempo, instruir a los miembros de dicha elite en modelos de integración a un contexto religioso caracterizado por la coexistencia de variadas formas de religiosidad. En su forma conservada, la segunda fue el producto de una sociedad en la que el cristianismo ortodoxo era, al menos en teoría, el marco normativo exclusivista en el que se apoyaba la monarquía. En consecuencia la traducción estandarizó los contenidos de acuerdo a un discurso sobre la alteridad pagana sustentado en modelos literarios previamente formulados. 


\section{O Bibliografía}

" Assemani, S. E. (Ed.). (1748). Acta ss. Martyrum Orientalium et Occidentalium. Roma: CoIlini. (=ASM).

" Bailey, H. W. (1943). Zoroastrian problems in the ninth-century books. Oxford: Clarendon Press.

" Barnes, T. (1985). Constantine and the Christians of Persia. Journal of Roman Studies, 75, 126-136.

" Barsoum, I.A. (2003 [1956]). The Scattered Pearls. A History of Syriac Literature and Sciences. Piscataway : Gorgias Press.

" Bayan, G. (Ed.). (1930). Le Synaxaire Armenién de Ter Israel. En Patrologia Orientalis 5.3, 65.2, 15.3, 16.1, 18.1, 19.1, 21.1-4. París: Firmin\&Didot.

» Becker, A. (2009). Martyrdom, Religious Difference and "Fear" as a Category of Piety in the Sassanian Empire. The Case of the Martyrdom of Gregory and the Martyrdom of Yazdpaneh. Journal of Late Antiquity, 2, 300-336.

» Bedjan, P. (Ed.). (1891-1897). Acta Martyrum et Sanctorum Syriace. París-Leipzig: Harrassowitz. (=AMS)

" Brock, S. (1998). Syriac Culture, 337-425. En A. Cameron y P. Garnsey (Eds.), The Cambridge Ancient History 327-425 (708-719). Cambridge: Cambridge University Press.

"Brock, S. (2008). The History of Mar Ma'in with a Guide to the Persian Martyr Acts. Piscataway: Gorgias Press.

»Brock, S. P. (1977). Greek into Syriac and Syriac into Greek. Journal fthe Syriac Academy, 3, 1-17.

» Burgess, R. (1999). The Dates of the Martyrdom of Simeon Bar Sabbāē and the Great Massacre. Analecta Bollandiana, 117, 9-66.

»Choksy, J. (1988). Sacral Kingship in Sasanian Iran. Bulletin of the Asia Institute, 32, 35-52.

"Christensen, A. (1944). L'Iran sous les Sassanides. Copenhague: P. Geuthner.

" Clark, G. (1991). Let Every Soul be Subject: The Fathers and the Empire. En L. Alexander (Ed.), Images of Empire (251-275). Sheffield: Sheffield Academic Press.

"Daryaee, T. (2008). Kingship in Early Sasanian Iran. En V. Sarkhosh Curtis y S. Stewart (Eds.), The Idea of Iran. Volume III. The Sasanian Era (60-70). Londres: I. B. Tauris.

"De Jong, J. (2006). Emperors in Egypt. The Representation and Perception of Roman Imperial Power in Greek Papyrus Texts from Egypt, AD 193-284.Nimega: Drukkerij Quickprint.

»Delehaye, H. (1905). Catalogus codicum hagiographicorum graecorum bibliothecae D. Marci venetiarum. Analecta Bollandiana, 24, 169-256.

»Delehaye, H. (Ed.). (1902). Synaxarium Ecclesiae Constantinopolitanae e códice Sirmondiano nunc Berolinensi, Adiectis synaxarisselectis. Propylaeum Acta Sanctorum Novembris. Bruselas: Socios Bollandianos.

»Delehaye, H. (Ed.). (1903). SS. Ionae et Barachisiimartyrum in Perside Acta graeca. Analecta Bollandiana, 22, 395-407.

》Delehaye, H. (Ed.). (1907). Les Versions grecques des Actes des Martyrs Persans. Textes grecs et traductions. En Patrologia Orientalis 2.4 (421-436). París: Firmin-Didot. (=Martirio de Jonás $(A)$ ). 
» Delehaye, H. (Ed.). (1907). Les Versions grecques des Actes des Martyrs Persans. Textes grecs et traductions. En Patrologia Orientalis 2.4 (436-439). París: Firmin-Didot. (=Martirio de Jonás $(B))$.

»Devos, P. (1946). Sainte Sirin martyre sous Khosrau ler Anosarvan. Analecta Bollandiana, $64,87-131$.

»Devos, P. (1953-1954). Le dossier hagiographique de S. Jacques L'Intercis. Analecta BoIlandiana, 71/72, 157-210/213-256.

»Devos, P. (1966). Les Martyrs Persans à travers leurs actes syriaques. En Atti del convegno sul teme La Persia e il mondo greco romano (213-225). Roma: Accademia Nazionale dei Lincei.

"Erhard, A. (1937-1952). Überlieferung und Bestand der hagiographischen und homiletischen Literatur der griechischen Kirche.Osnabrück: Zeller.

» Fiey, J. M. (1963). Tagrît. Esquisse d'histoire chrétienne. L'Orient Syrien, 8, 289-342.

» Fiey, J. M., \& Conrad, L. (2004). Saints Syriaques. Princeton: Darwin Press.

» Gignoux, P. (1972). Glossaire des Inscriptions Pehlevies et Parthes.Londres: LundHumphries.

» Gignoux, P. (1998). Anatomie et physiologie humaine chez un auteur syriaque, Ahudemmeh. Comptes-rendus des séances de l'Académie des Inscriptions et Belles-Lettres, 142 (1), 231-24.

» Gnoli, G. (1999). Farr(ah). En Encyclopaedia Iranica (312-316). Costa Mesa: Mazda.

» Grillet, B.ySabbah, G. (Eds. yTrads.). (1983). Sozomène: Histoire Ecclésiastique. Livres I-II. París: Cerf

» Herman, G. (Ed.). (2016). Persian Martyr Acts under King Yazdgird I. Piscataway: Gorgias Press.

" Hugonnard-Roche, H. (2014). La question de l'âme dans la tradition philosophique syriaque (Vle-IXe siècle). Studiagraeco-arabica, 4, 17-64.

» Jullien, C. (2016). Découverte d'un martyr perse dans un légendier latin médiéval. AnalectaBollandiana, 134 (1), 5-19.

» Jullien, F., \&Jullien, C. (2003). Les Actes de MārMāri. Lovaina: Peeters.

» Kalldelis, A. (2018). Catalogue of Translations into Byzantine Greek.https://www.google. com.ar/url sa $=t \& r c t=j \& q=\& e s r c=s \&$ source $=$ web \&cd $=1 \& c a d=r j a \& u a c t=8 \& v e d=2 a h$ UKEwj54cGUvYbfAhXKhJAKHbCkAloQFjAAegQICRAB\&url=http\%3A\%2F\%2Fwww. academia.edu\%2F36711128\%2FKaldellis_Catalogue_of_Translations_into_Byzantine_ Greek_version_III_\&usg=A (acceso el 4 de diciembre de 2018)

» Lagrange, F. (1852). Les Actes des Martyrs d'Orient.París: Belin.

» Land, J. P. (Ed.). (1875). Pauli Persae Logica. En J. P. Land (Ed.), Anécdota Syriaca IV (pp. I, 1-32 (texto), II, 1-30 (trad. latina)). Leiden: Brill.

"Latyshev, V. (Ed.). (1911-1912). Menologii anonymi Byzantini saeculi X quae supersunt: sumptibus Caesareae Academiae Scientiarum e Codice Mosquensi 376 Vlad. 7. San Petersburgo: S/P.

" Leclercq, H. (1902-1925). Les martyrs. Recueil des pièces authentiques sur les martyrs depuis les origines du christianisme jusqu'au XXe siècle.París-Tours: Mame.

»Lendon, J. (2001). Empire of Honour: The Art of Government in the Roman World. Oxford: Oxford University Press.

» Marguliés, A. (1927). Der altkirchenslavische Codex Suprasliensis. Heidelberg: Winter. 
" MartyrologiumRomanum. S/A (1583) Martyrologium Romanum ad novam Kalendarii rationem et ecclesiasticae historice veritatem restitutum, Gregorii XIII Pont. Max. iussueditum. Roma: TypographiaDomiiciBasae.

» Mercier, R. (1999). The Dates in Syriac Martyr Acts. En A. Burgess, y W. Witakowski (Eds.), Studies in Eusebian and Post-EusebianChronography (287-301). Stuttgart: Steiner.

» Musurillo, H. (Ed.). (1972). The Acts of the Christian Martyrs. Oxford: Oxford University Press.

»Panaino, A. (2007). Astral Characters of Kingship in the Sasanian and Byzantine Worlds. En Politica Religiosa e regalità Sacra nell'Iranpreislamico (pp. 143-182). Milán: Mimesis.

» Parmentier, L. (Ed.). (1911). Theodoret: Kirchengeschichte.Leipzig: Hinrichs.

»Peeters, P. (1922). Traductions et traducteurs dans l'Hagiographie Orientale á l'epoque byzantine. Analecta Bollandiana, 40, 241-298.

》Peeters, P. (1925). Le 'Passionnaire d’Adiabène. Analecta Bollandiana, 43, 261-304.

» Rapp, C. (2016). Brother-Making in Late Antiquity and Byzantium: Monks, Laymen, and Christian Ritual. Oxford: Oxford University Press.

" Ruiz Bueno, D. (1951). Actas de los mártires. Madrid : BAC.

» Severianov, S. (1904). Супрасльская рукопись. Petrogrado: Pamjatniki Staroslavjanskago Jazyka.

"Smith, K. (Ed.). (2014). The Martyrdom and History of Blessed Simeon Bar Sabbae. Piscataway: Gorgias press.

"Soudavar, A. (2003). The Aura of Kings: Legitimacy and Divine Sanction in Iranian Kingship. Costa Mesa: Mazda Publishers.

"Stern, S. (2004). Near Eastern Lunar Calendars in the Syriac Martyr Acts. Le Museon, 117/3-4, 447-472.

"Sundermann, W. (1988). Ke cihr az yazdän. Zur Titulatur der Sasanidenkönige. Archív Orientalní, 56, 338-340.

» Taylor, R. (1994). The Peshitta of Daniel. Leiden: Brill.

»Ubierna, P. (2020a). Translations I: Greek Texts into other Languages (4th - 15 th C.). En S. Papaioannou (Ed.), The Oxford Handbook of Byzantine Literature (1-22). Oxford: Oxford University Press.

»Ubierna, P. (2020b). Translations II: From Contemporary Languages into Greek. II: Syriac. EnThe Oxford Handbook of Byzantine Literature. (1-22). Oxford: Oxford University Press.

»Widengren, G. (1959). The Sacral Kingship of Iran. En Edsman, C. M. (ed.), The Sacral Kingship. Studies in the History of Religions 4 (242-257). Leiden: Brill.

»Wiessner, G. (1967). Zur Märtyrer-überlieferung aus der Christenverfolgung Schapurs II.Göttingen: Vandenhoeck\&Ruprecht.

"Wilmhurst, D. (2000). The Ecclesiastical Organisation of the Church of the East, 1318-1913. Lovaina: Peeters.

》Wood, P. (2013). The Chronicle of Seert and Roman Ecclesiastical History in the Sasanian World. En P. Wood (Ed.), History and Identity in the Late Antique Near East (43-59). Oxford: Oxford University Press.

» Zakeri, M. (1995). Sasanid Soldiers in Early Muslim Society: the Origins of 'Ayyārān and Futuwwa.Wiesbaden: Harrassowitz. 
